\title{
RBEP
}

\section{A formação do professor em Rodas de Formação}

Fernanda Medeiros de Albuquerque

Maria do Carmo Galiazzi

\section{Resumo}

Para a formação do profissional da educação é essencial que existam momentos de partilhas para tecer uma rede de relações e proporcionar a construção do conhecimento. As Rodas de Formação possibilitam que os educandos exponham suas dificuldades, desafios e conquistas, além de oportunizar a busca em conjunto de estratégias de superação. É objetivo deste artigo apresentar o processo de formação inicial de licenciandos de Química da Universidade Federal do Rio Grande (Furg), participantes do Programa Institucional de Bolsa de Iniciação à Docência (Pibid) no ano de 2009, por meio da sua inserção em Rodas de Formação. Durante o curso, o licenciando é incentivado a escrever suas preocupações com a sala de aula, além de registrar suas ideias, saberes e sugestões, sendo a escrita uma possibilidade de reflexão do seu processo de formação. O espaço de partilha de argumentos e a insistência no exercício da escrita possibilitam uma maior segurança no momento de tomar decisões e reavaliar as decisões tomadas.

Palavras-chave: formação de professores; escrita. 


\section{Abstract \\ Teachers education in Education Wheels}

It is essential to share moments in order to build a relation network and build knowledge concerning teachers education. The Education Wheels enable the exposure of difficulties, conquests and obstacles, as well as, the collective search for strategies to overcome them. The goal of the present article is to present the initial education process of Chemistry students of the Rio Grande Federal University who took part in the Pibid Program in 2009 through the Education Wheels. During the course, students are motivated to write down their worries, ideas and share their knowledge and suggestions focusing on classroom; in this sense, the writing activity is a possibility of reflection about their education process. The sharing space and the act of insisting in the writing exercise create a higher level of security in the moment of making and reevaluating decisions.

Keywords: teachers education; writing.

\section{Introdução}

Pretende-se com este artigo apresentar as diferentes Rodas de Formação de que podem participar os licenciandos de Química da Universidade Federal do Rio Grande (Furg), bem como destacar a importância da partilha e da escrita na constituição deste profissional da educação. O artigo está dividido em três partes: A formação do professor em Rodas de Formação, em que se discute a importância da partilha na formação do profissional da educação; A escrita no processo de formação de professores, em que se defende a importância do registro como possibilidade de reflexão; e As Rodas de que participam os licenciandos de Química da Furg, em que são apresentadas as Rodas dos Estágios e a Roda do Programa Institucional de Bolsa de Iniciação à Docência (Pibid).

\section{A formação do professor em Rodas de Formação}

Ao longo da nossa trajetória de vida fazemos parte de muitas rodas: roda da merenda, roda das brincadeiras, roda de samba, roda de amigos, roda do chimarrão, roda de professores, roda de estudo. Muitas são as trocas feitas nessas diferentes rodas; muito se aprende, se conhece e se socializa. A inserção ou não do sujeito em determinadas rodas depende de 
suas características e das relações estabelecidas ao longo da sua história. Mas, antes, é preciso saber que cada uma tem suas regras e limitações: nas rodas da merenda, é fundamental que todos os presentes tenham acesso ao alimento; nas rodas de chimarrão, todos os adeptos devem saber que não se agradece o mate; nas brincadeiras, todos devem cantar as cantigas de roda.

Essa configuração em roda facilita a comunicação. Os sujeitos conseguem se olhar, e, com isso, as interações acontecem com mais facilidade. Ocorrem trocas de olhares, trocas de argumentos, trocas de críticas, trocas de experiências. Quando se está em roda, as trocas acabam sendo inevitáveis; conseguimos por meio dela conhecer um pouco do outro, observando seu comportamento, suas reações e manifestações.

Porém, quando nos referimos à Roda de Formação, não utilizamos mais a palavra troca, mas sim partilha. Mas qual a diferença? Para a autora Cecília Warschauer (2001), partilha não tem a mesma perspectiva quantificável que a troca. Na partilha é necessário dar sem receber imediatamente. O sujeito aprende mais quando ensina a outros o que ele sabe. É entendido, portanto, que as Rodas de Formação trazem a ideia de retorno à pessoa, na qual o que importa são os significados e os aprendizados que elas fazem.

As Rodas de Formação se destacam pela qualidade das partilhas entre os participantes. Nessa Roda, todos têm algo a ouvir e algo a dizer. Essa configuração, com o objetivo de formar-se formando, nos mostra a possibilidade de construção de um espaço em que as aprendizagens se constroem por meio da relação entre os sujeitos.

Acreditamos que as Rodas de Formação sejam espaços que retiram o professor do isolamento e impulsionam o desenvolvimento de sujeitos pesquisadores da sua prática, contribuindo para a sua formação e para a formação dos seus pares. Nessas Rodas são dadas oportunidades para a partilha de experiências e, consequentemente, para o surgimento de questionamentos que incentivam a busca de novos argumentos que possam ser divulgados na própria Roda. Nela têm-se questionamentos, constroem-se coletivamente novos argumentos e se discutem os argumentos construídos para serem divulgados na Roda e fora dela.

Quando se organiza um grupo de formação em Rodas, seja esse constituído por alunos, professores em formação ou professores em exercício, a presença de diferentes pontos de vista impulsiona as aprendizagens. As discussões de experiências, juntamente com o estudo de textos teóricos, propiciam a reflexão entre teoria e prática, possibilitando a partilha das experiências, das interpretações, da relação entre elas e das possibilidades de por em prática o que é discutido.

A exposição de ideias e a oportunidade de partilha de histórias, de experiências vividas, de saberes e de dificuldades encontradas possibilitam que os participantes percebam que os problemas que enfrentam são também enfrentados por outros. Seja o participante um professor ou um aluno, ele receberá o incentivo para enfrentar os problemas, pois terá a força do conhecimento construído a partir da partilha e da reflexão coletiva. 
Quando narra sua experiência, um participante propicia a reflexão em outros. As histórias contadas na Roda não precisam ser iguais para que cada um faça a relação mais conveniente para si; a relação será feita a partir das experiências teóricas e práticas de cada um.

No livro intitulado A roda e o registro, Cecília Warschauer (1993, p. 56) recomenda que se tenha cuidado para que as conversas na Roda não se tornem mero "bate-papo" e destaca a necessidade do registro, que "é um grande instrumento para a sistematização e organização dos conhecimentos".

O registro faz com que as conversas nas Rodas sejam formalizadas e eternizadas. Ocorre um comprometimento maior com o que é falado e se oportuniza a socialização com outras Rodas de Formação. Quando registramos, conseguimos depois ler e refletir sobre a nossa caminhada. Podemos acompanhar o andamento da Roda, os conflitos gerados, os problemas vividos e as estratégias encontradas para tentar resolvê-los. O registro dos encontros, o registro individual e a escrita de histórias podem ser maneiras de eternizar alguns momentos vividos na Roda ou a partir dela.

Salientamos que o registro dos encontros não deva ser compreendido como a escrita de uma ata de reunião e com o formalismo que esta requer. No registro dos encontros da Roda existe a possibilidade de contar a história daquele encontro. Nesse caso o relator tem a liberdade de relacionar o que está sendo dito com o que está sendo estudado, confrontando teoria e prática e assumindo o papel de autor que conta e reflete sobre a Roda na Roda. É importante que se tenha alternância entre os autores para que cada um tenha a oportunidade de expor o seu ponto de vista, fazendo uma leitura crítica do encontro. O conjunto desses registros é um material que retrata a caminhada de formação daquele grupo e, posteriormente, poderá servir de contribuição para a formação de outros sujeitos e de outras Rodas.

Além do registro do encontro da Roda, a escrita individual pode ser também uma estratégia do participante para conseguir organizar sua ação e refletir sobre o que foi e está sendo feito. Essa reflexão oportunizará que ele perceba as lacunas existentes nos seus saberes, para que, a partir delas, busque um aprofundamento teórico, colaborando para novas discussões na Roda. Portanto, os dilemas, as ações, os obstáculos, os saberes e a iniciativa de cada um servem de combustível para fazer com que os encontros na Roda aconteçam de maneira proveitosa.

Ao mesmo tempo em que cada participante alimenta a Roda, a Roda consegue alimentar e impulsionar outras reflexões no indivíduo. Durante uma conversa na Roda, um tema iniciado pode ser questionado por um e desviado por outro sem que se perca a qualidade da partilha, fazendo com que o ritmo da Roda seja dado pela maneira como cada sujeito é afetado pelo assunto tratado. Souza (2010, p. 122) destaca essa característica da Roda, intitulando uma das histórias contadas na sua tese como "A Roda tem dessas coisas: uma história puxa outra!", em que ele narra um dos encontros da Roda de Estágio da Furg. 
Outra possibilidade de registro da Roda é a escrita de histórias de sala de aula. Dessa forma, o autor poderá narrar histórias que ocorreram ou foram inventadas por ele numa possibilidade de criação de um "território de produção de conhecimento na formação da pessoa" (Barcelos; Silva, 2010. p. 150). A leitura e a escrita de histórias aparecem como momentos em que as aprendizagens acontecem, quando o imaginário permite a soltura de amarras com o racional, oportunizando a cada leitor a interpretação de acordo com a sua realidade, suas crenças e experiências e seus saberes.

Sabe-se que é fundamental para o crescimento do grupo a socialização de experiências e de saberes. A leitura das histórias pelos demais participantes da Roda faz com que um conheça o outro, além de se conhecer. Essa partilha entre os sujeitos oportuniza que as fragilidades apareçam e que novas reflexões sejam fomentadas. As novas reflexões servirão novamente de combustível para a Roda de Formação, oportunizando que cada participante seja um sujeito formador, peça fundamental para a Roda a que pertence.

O desafio de se reconhecer como sujeito formador está atrelado a um processo de acompanhamento, reflexão e posicionamento perante as questões de conflito reveladas por si. Sendo ele o primeiro leitor da sua história, escreve e reflete sobre o que está posto em um movimento de intensa contribuição para a sua formação. Perceber-se como fazedor de histórias (marcado por nosso inacabamento), ser dono de seu destino, é crucial no processo de formação desse sujeito pensante, autor e construtor de conhecimento (Freire, 2008, p. 43).

As contribuições que uma história dá para a outra são inevitáveis. O leitor será afetado pela escrita de acordo com a sua trajetória, suas experiências e seus valores, desencadeando um processo de apropriação e construção de histórias. O que foi contado por um influencia na escrita do outro, de acordo com a relação estabelecida entre o que se lê e o que se acredita. A compreensão do sujeito enquanto indivíduo formador está conectada com a percepção que ele tem sobre as implicações que suas histórias causam nos demais participantes.

\section{A escrita no processo de formação do professor}

A pesquisa como modo de construção de conhecimento de alunos e professores é defendida por muitos autores, por exemplo, Demo (2002) e Moraes; Ramos e Galiazzi (2004), como uma das possibilidades de melhoria do ensino. Acreditando que exista uma correlação fortíssima entre a qualidade do trabalho do professor e a aprendizagem do aluno (Demo, 2000), entende-se a importância do incentivo à formação de professores pesquisadores da sua própria prática. Essa postura de sujeito pesquisador oportunizará que o professor se torne semeador da prática da pesquisa e a desenvolva como uma atitude cotidiana na sua sala de aula (Demo, 2002). Porém, como formar professores pesquisadores da sua prática? 
O trabalho com a escrita da prática docente, desenvolvido ao longo do processo de formação inicial, oportuniza que o sujeito se perceba como pesquisador da sua trajetória. Por meio da pesquisa ele terá possibilidade de desenvolver o hábito de refletir, questionar, buscar respostas, construir argumentos críticos, se comunicar e se entender sempre como sujeito incompleto (Galiazzi, 2003). Pode ser por meio da escrita que o licenciando irá se tornar consciente das coisas. Portanto, pode ser por meio da escrita da sua prática que o sujeito pode se tornar pesquisador dela.

Constituímo-nos de acordo com as histórias que ouvimos e que nos marcaram. Crescemos ouvindo histórias e as repetimos de acordo com nossas crenças, nossos valores, nossa cultura e nossa história. Alguns já devem ter ouvido falar das histórias contadas por Sherazade durante mil e uma noites. Ela criava e recriava histórias, encantando o rei Shariar e fazendo com que a sua imaginação acompanhasse os personagens, heróis e heroínas. Portanto, passamos a vida recriando histórias, de acordo com a situação que estamos vivendo e com o que acreditamos e queremos.

Sabemos que uma narrativa envolve uma sequência de eventos, mas nem toda sequência de eventos merece ser contada (Bruner, 2001). Contamos aquilo que pode interessar ao outro ou a nós mesmos. "Acontecimentos banais e previsíveis não se prestam a serem contados." (Bastos, 2005). Contamos para responder questionamentos, para resolver angústias, para nos revelar, para nos conhecer. Escolhemos o que vamos contar e como iremos contar. Essa escolha faz com que mostremos apenas o que queremos que seja mostrado, pois quando contamos uma história enviamos uma mensagem a alguém, mesmo que este alguém sejamos nós mesmos. Dessa forma, o outro nos conhece e nos interpreta a partir das histórias que contamos.

No entanto, a narração é sempre uma ficção, pois nunca contamos o próprio fato, mas outra coisa. Contamos aquilo que conseguimos contar, e, ao contar, deixamos a história sujeita à interpretação do outro. O narrador, portanto, conta sua experiência dando oportunidade para que o outro a escute e a transforme de acordo com a sua interpretação (Souza, 2010). Muitas vezes questionamos o nosso ouvinte quando ele comenta a história que contamos, reclamamos que não foi bem aquilo que foi dito. Mas o ouvinte é livre para fazer a interpretação que quiser, de acordo com as relações que ele conseguiu fazer. Depois que é contada, a história não pertence mais a ninguém, estando sujeita a diversas interpretações.

Quando ouvimos ou lemos uma história, ela estabelece ou não relação com o que acreditamos, e, ao recontá-la, deixamo-la impregnada pela nossa interpretação. Portanto, há necessariamente adaptações ao contexto e aos ouvintes, pois a interpretação da narrativa é profundamente afetada por circunstâncias culturais e históricas (Bruner, 2001). As narrativas são, portanto, construções de um narrador em diferentes momentos de sua experiência (Bastos, 2005). Quando contamos histórias, estamos recriando o contexto do evento narrado, localizando-o no tempo e no espaço, introduzindo personagens, ações e falas. 
Uma história narrada ganha outras possibilidades de interpretação que dependem das características e do momento em que se encontra o leitor. Quando escreve, a pessoa está fazendo um convite para o diálogo, está se revelando para si e para os outros. Nesse diálogo, nem sempre a intencionalidade da escrita será percebida pelo leitor. As concepções reveladas por quem escreve só irão atingir o que o leitor puder e tiver condições de perceber, sendo este livre para refletir qual mensagem o autor quis passar. Muitas leituras nos incomodam e nos fazem questionar, outras reafirmam o que acreditamos, existem, porém, aquelas que rapidamente caem no esquecimento.

Uma história que nos chocou em determinado momento da vida (ou aquela que não nos tocou) pode nos entusiasmar em outros e fazer com que reflitamos, a relacionemos com o que estamos vivendo, interpretemo-la e a recontemos a outros. Como já foi dito anteriormente, o narrador conta apenas o que consegue; o ouvinte, porém, é livre para interpretar da maneira como quiser.

A narrativa pode ser feita de forma oral ou escrita, e estas apresentam diferenças fundamentais. Quando escrevemos, eternizamos o que foi narrado. A escrita atravessa o tempo, possibilitando que hoje possamos saber o que se escreveu há milhares de anos. Ela também atravessa o espaço, pois podemos enviar histórias para diversos lugares do mundo. A escrita, portanto, apresenta um caráter de permanência e amplitude que a fala não consegue atingir.

O caráter de permanência atingido pelo registro das histórias contadas possibilita a reavaliação e a crítica de nossas atuações passadas, veiculando atitudes e emoções em relação a elas. Mas a quem cabe contar histórias? O que merece ser contado? O que merece ser lido? Acreditamos que muitas experiências devam ser narradas e partilhadas. Temos que assumir a posição de contadores de histórias, e não passar a vida apenas como ouvintes das histórias que nos contam. Temos que escrever a nossa história.

Bruner (2001) acredita que uma história tem dois lados: uma sequência de eventos e uma avaliação implícita dos eventos contados. A história, portanto, traz consigo a avaliação que o sujeito faz sobre o fato. Só por ter escolhido contar uma história e não outra, o sujeito já demonstra a importância que dá para determinado fato.

Nas escolas, a escrita de histórias narradas por professores pode surgir como fundamental incentivo para que eles assumam a autoria e a reflexão sobre o ambiente escolar, recriando seus saberes, problematizando experiências e possibilitando a transformação da sua prática. Mediante a narrativa, vamos explicitando contradições, conflitos e limites que percebemos na nossa formação (Souza, 2010). A narrativa, portanto, poderá ser mais uma possibilidade que o professor tem para refletir sobre a docência, oportunizando que tome decisões de acordo com os questionamentos provocados por sua escrita.

No processo de escrita, os professores transformam-se em narradores de suas próprias experiências pedagógicas (Suárez, 2008). Com isso, eles 
reconstroem parte da sua trajetória profissional, atribuindo sentidos ao que fizeram em determinados momentos. A escrita é uma maneira de o professor conversar sobre suas preocupações e expectativas com os interlocutores.

Quando narra uma história de sala de aula, o professor conta uma sequência de eventos não para explicar o que está sendo contado, mas para sujeitar a história a diferentes interpretações, sendo possível, por meio dela, eliminar a dúvida do ouvinte e, principalmente, a dúvida dele mesmo. A narrativa é um modo como organizamos as nossas experiências; é por meio dela que podemos refletir e avaliar como os fatos ocorreram, as consequências desses fatos, os porquês das consequências e o que poderia ter sido feito diferente. Dessa forma, podemos eliminar as dúvidas e contribuir para a nossa formação.

Sabe-se que o hábito de escrever histórias de sala de aula não é cultivado pelas escolas, pois normalmente a escrita do professor é dedicada ao preenchimento de cadernos de chamada, a atas de reuniões ou a pareceres de alunos. São raros os momentos em que o professor tem a oportunidade de parar e questionar a sua prática. Nas reuniões de professores, em que seria possível a constituição de uma Roda de Formação para a partilha e o registro das experiências daquele grupo, as forças são concentradas no aproveitamento do aluno e não no trabalho do professor.

É fundamental perceber a importância da narrativa na formação do professor, pois, quando se coloca como protagonista da sua história, ele projeta suas expectativas e preocupações. Narrando, os professores compartilham e conversam com os colegas numa linguagem prática, com suas próprias palavras, pois, por meio da escrita e da leitura de histórias, eles podem discutir problemas, dúvidas e aflições comuns (Suárez, 2010).

Por meio da escrita, o professor consegue distanciar-se das suas certezas e incertezas e visualizar o que até então estava oculto na sua percepção enquanto formador. Portanto, ao contar histórias de sala de aula, o professor estará contribuindo para o seu processo de formação (Souza, 2010). Os docentes que assumem o papel de autor compartilham suas leituras de mundo, trajetórias e saberes pedagógicos com colegas e conhecedores da linguagem pedagógica.

É importante que, durante seu processo de formação, o licenciando seja incentivado a refletir sobre a sua prática por meio da escrita. O hábito de escrever sua própria história irá permitir que o professor em formação, a partir da sua linguagem, perceba suas lacunas e busque estratégias para se qualificar como docente. As contradições, os conflitos, as resistências e os limites do processo de formação do professor, ao serem narrados, podem contribuir para a sua compreensão e provocar mudanças (Souza, 2010).

É preciso muita coragem para escrever histórias. Essa escrita nos desacomoda e nos faz refletir e mudar como profissional e como pessoa. Tem-se por meio dela a possibilidade de expor modelos de bem e de mal num exercício de autoconhecimento e amadurecimento. A oportunidade de escrever histórias propicia que o sujeito consiga revelar e refletir sobre seus medos, desejos e angústias. 
A escrita é uma atividade complexa e difícil de ser realizada. Para escrever, devemos selecionar, planejar e organizar nossas ideias, nossos sentimentos, nossos saberes e não saberes; devemos nos revelar ao olhar crítico do outro, mostrando nossas certezas em uma tarefa individual, solitária. No exercício da escrita, deixamos a nossa marca, e o sujeito que lê dá outra vida ao que está registrado. O olhar do leitor depende do seu contexto de vida, das suas concepções de mundo e do momento em que está lendo. Nós, como primeiros leitores da nossa escrita, somos também nossos primeiros críticos.

É exatamente dessa crítica que o professor precisa; a reflexão e o olhar crítico sobre sua prática são fundamentais para a sua formação. O professor precisa perceber-se como autor da sua história, fazendo com que ela seja modificada de acordo com as avaliações que faz. Trata-se de um processo de autoconhecimento, avaliação e reavaliação do seu papel como profissional da educação.

\section{As Rodas de que participam os licenciandos de Química da Furg}

O curso de Química da Furg possui, desde 2004, cinco disciplinas de estágios que possibilitam o contato intenso do licenciando com a escola. Cada um deles tem a carga horária desenvolvida em atividades na universidade, com os professores responsáveis pelas disciplinas, e na escola, com o envolvimento do professor de Química na condição de professor-tutor. Nos encontros na universidade, o objetivo é um processo de formação permanente, em Rodas de Formação.

A disciplina de Estágio I, oferecida no segundo semestre do segundo ano do curso, tem como objetivo a observação e ambientação com a sala de aula da escola. O licenciando deve relatar sua caminhada em um portfólio, possibilitando que a escrita e a reflexão comecem a fazer parte da vida do futuro professor. O Estágio II tem como foco a experimentação, o III, a análise e escolha do livro didático, o IV, a elaboração e execução de Unidades de Aprendizagem, e o V, por fim, a docência. Todos os estágios têm o portfólio reflexivo como incentivador da escrita e análise da prática; nele, as narrativas mantêm o caráter formativo, um lugar de diálogos entre licenciando e professores formadores. O portfólio assume, neste caso, o atributo de constituir-se numa espécie de "documento de identidade" (Souza, 2010, p. 75).

Desde o início do curso, o licenciando tem a oportunidade de estar em contato com o ambiente escolar, podendo, com isso, refletir sobre a prática docente em uma Roda de Formação constituída por seus colegas de graduação e pelo professor da disciplina de Estágio. Nessa Roda de Formação, o licenciando é incentivado a escrever suas preocupações com a sala de aula, além de registrar suas angústias, ideias e sugestões em um portfólio que registrará a sua caminhada como professor que está se constituindo.

Durante a tentativa de escrever sobre sua prática, o licenciando consegue refletir sobre seu conhecimento de modo mais consistente. 
Esse processo possibilita a tomada de consciência sobre as fragilidades e as potencialidades em relação ao que se faz, ao mesmo tempo em que consolida o conhecimento profissional. A escrita oportuniza a percepção das dúvidas e lacunas sobre as ações e os saberes da docência.

O aluno de graduação pode perceber, ao longo dos estágios, as dificuldades que irá encontrar na sala de aula. Propõe-se, nas Rodas dos estágios, o aprofundamento de questões, surgidas no ambiente escolar, que representam dificuldades vivenciadas pelo professor no seu exercício profissional; elas têm como objetivo central um estudo aprofundado da realidade escolar, oportunizando aos futuros professores atividades de ensino que favoreçam a construção do conhecimento. As atividades desenvolvidas no decorrer do curso de formação devem considerar o Estágio como um espaço privilegiado de questionamento e investigação (Pimenta, 2010).

Outra Roda de Formação em que o licenciando de Química da Furg pode participar é no Pibid, aprovado na Furg em 2008 e em andamento desde janeiro de 2009. Com objetivos que vão ao encontro dos estabelecidos para o curso, o Programa visa antecipar o vínculo entre os futuros professores e as salas de aula da rede pública.

A Furg participa do Pibid com dez licenciaturas envolvidas - Química, Física, Biologia, Matemática, Inglês, Espanhol, História, Artes, Português e Pedagogia -, em um trabalho interdepartamental e interdisciplinar na universidade. O projeto institucional, com suas ações previstas para dois anos, contempla licenciandos bolsistas (podendo envolver outros licenciandos voluntários), professores supervisores da rede pública e, no mínimo, em média, 2.000 alunos da educação básica, uma vez que a mesma escola pode ser contemplada por diferentes áreas do conhecimento.

Nessa Roda do Pibid de Química, a escrita continua oportunizando momentos fundamentais no processo de formação do professor, sendo incentivada por meio de várias atividades, como escrita de um portfólio coletivo (escrita do professor do ensino básico com os licenciandos que atuam na escola), escrita de uma história mensal, leitura e comentário de uma história mensal, escrita semestral de um relato sobre a sala de aula, construção de uma Unidade de Aprendizagem, entre outras sugeridas ao longo do Programa.

A escrita de histórias tem como objetivo a escrita, a leitura e a reflexão acerca da sala de aula. O portfólio coletivo foi pensado com o objetivo de registrar as histórias e angústias a partir de um tema escolhido pelo grupo, que é formado pelo professor-tutor e os licenciandos que o acompanham, e cada um deve fazer o registro no material duas vezes ao mês. No portfólio também são discutidas reflexões de atividades feitas em sala de aula.

As Rodas citadas anteriormente e a Roda do Pibid de Química têm muitas semelhanças e contribuições no processo de formação do educando. Portanto, o aluno do curso de licenciatura em Química da Furg, que é também aluno bolsista do Pibid, além de cursar os cinco estágios e ter o contato com a escola desde cedo, pode ter um espaço de formação 
contando com a presença e participação do seu professor-tutor e demais professores da rede pública, conhecendo outras realidades e maneiras de enfrentá-las. Ele tem a oportunidade de, toda a semana, nas Rodas do Pibid, partilhar ideias e planejar com o professor da escola, partilhar ideias com os outros professores e colegas e expor o que pensa.

Dessa forma, o contato é mais próximo do que o encontro feito apenas na escola - é feito numa Roda de Formação, com múltiplos olhares. Nela o licenciando tem a oportunidade de partilhar experiências, contribuindo para a sua formação e para a formação de colegas e professores.

\section{Conclusão}

É necessário que, durante a graduação, o licenciando vivencie momentos em que construa seu conhecimento e viva situações a serem enfrentadas na sua vida profissional. O conhecimento construído nas partilhas e na reflexão coletiva encoraja e incentiva o enfrentamento de problemas encontrados na sala de aula, além de oportunizar a tomada de consciência do seu papel como indivíduo formador.

O diálogo verbal e escrito em uma Roda de Formação propicia que o participante sinta que não está sozinho e que as suas dificuldades são comuns a outros. Portanto, a formação do sujeito em Rodas oportuniza que ele socialize suas experiências e saberes, aprofundando a reflexão sobre suas ações.

Nas diferentes Rodas de Formação de que participam os licenciandos de Química da Furg, a escrita aparece como uma importante possibilidade de reflexão do processo de formação do ser professor. Por meio dela o autor consegue planejar e organizar suas ideias, expondo suas concepções ao olhar do outro. Com a escrita o aluno consegue perceber suas dúvidas e lacunas, mediante o registro da sua trajetória de formação como professor. Ao expor suas contradições, seus conflitos, suas resistências e os limites do seu processo de formação, o professor tem a possibilidade de refletir sobre o seu papel como profissional da educação e provocar mudanças.

\section{Referências bibliográficas}

BARCELOS, Valdo Hermes de Lima; SILVA, Ivete Souza da. Leituras e escritas reais... escrituras imaginárias: repensando o lugar da leitura e da escrita na educação. In: BARCELOS, Valdo Hermes de Lima; ANTUNES, Helenise Sangoi. Santa Cruz do Sul: Edunisc, 2010.

BASTOS, Liliana Cabral. Contando estórias em contextos espontâneos e institucionais: uma introdução ao estudo da narrativa. Calidoscópio, São Leopoldo, v. 3, n. 2, p. 74-87, maio/ago. 2005. 
BRUNER, Jerome Seymour. A cultura da educação. Porto Alegre: Artmed, 2001.

DEMO, Pedro. Conhecer e aprender: sabedoria dos limites e desafios. Porto Alegre: Artes Médicas, 2000.

. Educar pela pesquisa. 5. ed. Campinas: Autores Associados, 2002.

FREIRE, Madalena. Educador, educa a dor. São Paulo: Paz e Terra, 2008.

GALIAZZI, Maria do Carmo. Educar pela pesquisa: ambiente de formação de professores de Ciência. Ijuí: Unijuí, 2003.

MORAES, Roque; RAMOS, Maurivan Güntzel; GALIAZZI, Maria do Carmo. Pesquisa em sala de aula: fundamentos e pressupostos. In: MORAES, Roque; LIMA, Valderez Marina do Rosário. Pesquisa em sala de aula: tendências para a educação em novos tempos. Porto Alegre: Edipucrs, 2004.

PIMENTA, Selma Garrido; LIMA, Maria Socorro Lucena. Estágio e docência. São Paulo: Cortez Editora, 2010. 296 p.

SOUZA, Moacir Langoni de. Histórias de constituição e ambientalização de professores de química em rodas de formação em rede: colcha de retalhos tecida em partilhas (d)e narrativas. 2010. 182f. Tese (Doutorado em Educação). Programa de Pós-Graduação em Educação Ambiental. Universidade Federal do Rio Grande (Furg). Rio Grande, RS.

SUAREZ, Daniel H. A documentação narrativa de experiências pedagógicas como estratégia de pesquisa-ação-formação de docentes. In: PASSEGI, Maria da Conceição; BARBOSA, Tatyana Mabel Nobre. Narrativas de formação e saberes biográficos. Natal: EDUFRN; São Paulo: Paulus, 2008.

WARSCHAUER, Cecília. Rodas em rede: oportunidades formativas na escola e fora dela. Rio de Janeiro: Paz e Terra, 2001.

A roda e o registro: uma parceria entre professor, alunos e conhecimento. Rio de Janeiro: Paz e Terra, 1993.

Fernanda Medeiros de Albuquerque, doutoranda em Educação em Ciências: Química da Vida e Saúde, pela Universidade Federal do Rio Grande (Furg), é professora e coordenadora de extensão do Instituto Federal de Educação, Ciência e Tecnologia do Rio Grande do Sul (IFRS).

fernanda.albuquerque@osorio.ifrs.edu.br 
Maria do Carmo Galiazzi, doutora em Educação pela Pontifícia Universidade Católica do Rio Grande do Sul (PUC-RS), é professora associada da Universidade Federal do Rio Grande (Furg), atuando como professora do curso de Química Licenciatura e nos programas de PósGraduação em Educação Ambiental e Educação em Ciências: Química da Vida e Saúde.

mcgaliazzi@gmail.com

Recebido em 28 de setembro de 2010.

Aprovado em 25 de maio de 2011. 